\title{
DO PROFESSOR REAL AO PROFESSOR IDEAL OU VICE-VERSA: A REPRESENTAÇÃO DO PROFESSOR DE HISTÓRIA NO DISCURSO HISTORIOGRÁFICO
}

Renilson Rosa Ribeiro*

RESUMO:

O presente artigo analisa os principais debates historiográficos correntes sobre o papel do professor de História no Brasil nas últimas duas décadas (1980 e 1990). O estudo do ofício deste profissional da História, de maneira geral, insere-se nos debates sobre a reforma do ensino desta disciplina iniciada no final dos anos 1970 e começo dos 1980 no Brasil.

PALAVRAS-CHAVE:

Ensino; Professores; Historiografia.

"O que fabrica o historiador quando" faz história? Para quem trabalha? Que produz? Interrompendo sua deambulação erudita pelas alas dos arquivos, por um instante ele se desprende do estudo monumental que o classificará entre seus pares, e, saindo para a rua, ele se pergunta: O que é esta profissão?".

Michel de Certeau - A Escrita da História (Rio de Janeiro, 2000)

\section{Olhares no espelho}

Na compreensão de um número significativo de pessoas, ensinar História parece ser algo muito simples de se fazer. Poucos conseguem perceber, todavia, as diversas questões teóricas, metodológicas e ideológicas presentes a cada passo

\footnotetext{
*Bacharel e Mestrando em História pela Universidade Estadual de Campinas.
} 
da aula de História. Às vezes, nem mesmo o próprio professor de História, "habituado" a repetir o mesmo assunto em diferentes turmas, consegue refletir que o caminho discursivo que segue é somente um dentre duas alternativas possíveis de serem trilhadas ${ }^{1}$.

Nas últimas décadas a relação entre a formação do professor de História e a sua prática cotidiana na sala de aula vem sendo pauta de encontros, congressos, seminários e publicações ${ }^{2}$, especialmente em épocas de reforma curricular. Nessas discussões está presente, nas falas de professores e pesquisadores, a necessidade de serem realizados mudanças, com o desejo de superar o modelo de ensino tradicional de História no ensino fundamental, médio e, também, no ensino superior ${ }^{3}$.

Esses debates sobre o ensino de História no Brasil tornamse bastante intensos e acirrados especialmente em momentos de elaboração e implantação de novos currículos, como por exemplo

${ }^{1}$ ROCHA,Ubiratan. Reconstruindo a História a partir do imaginário do aluno. In: NIKITIUK, Sônia L. (org.) Repensando o ensino de História, 2. ed. São Paulo: Cortez, 1999, p. 47.

2 São significativos dentro destes encontros organizados para a discussão do ensino de História no Brasil o I Seminário Perspectivas do Ensino de História (1988) e o II Seminário Perspectivas do Ensino de História (1996), ambos realizados na Faculdade de Educação da Universidade de São Paulo; o III Seminário Perspectivas do Ensino de História (1998), na Universidade Federal do Paraná; o I Encontro de Professores e Pesquisadores em Ensino de História (1993), na Universidade Federal de Uberlândia; o II Encontro de Professores e Pesquisadores em Ensino de História (1995), na Universidade Federal Fluminense; o III Encontro Nacional dos Pesquisadores do Ensino de História (1997), na Universidade Estadual de Campinas; e o IV Encontro Nacional dos Pesquisadores do Ensino de História (1999), na Universidade de Ijuí. SCHMIDT, Maria A A formação do professor de História e o cotidiano da sala de aula. In: BITTENCOURT, Circe Maria F.(org.) O saber histórico na sala de aula, 2. ed. São Paulo: Contexto, 1998, p. 54.

${ }^{3}$ SCHMIDT, Maria A A formação do professor de História e o cotidiano da sala de aula. In: BITTENCOURT, Circe Maria F. (org.) O saber histórico na sala de aula, 2. ed. São Paulo: Contexto, 1998, p. 54. 
a nova $\mathrm{LDB}^{4}$ e os Parâmetros Curriculares Nacionais para o ensino fundamental. Percebe-se, nestes debates, o confronto entre diferentes concepções de História, currículo, ensino, professor e aluno. Posturas acadêmicas que defendem, por exemplo, a imagem do professor de História como "difusor" e "transmissor", quando não "vulgarizador", passivo de conhecimentos produzidos pela academia ${ }^{5}$ passam a ser criticadas e contrapostas pela do professor "produtor de saberes e fazeres".

Entre os textos e as leituras feitas sobre a temática manifestou-se a necessidade de enfrentar questões relacionadas à modernização dos currículos de $1^{\circ}, 2^{\circ}$ e $3^{\circ}$ graus e à qualificação e atualização de professores de História?.

A partir deste contexto de revisão da História ensinada, o presente ensaio apresenta-se com o objetivo de analisar a construção da representação do "fazer" (prática) do professor de História do ensino fundamental e médio (atuais designações para o $1^{\circ}$ e $2^{\circ}$ graus) no discurso historiográfico dentro dos debates sobre a Reforma Curricular nas escolas brasileiras nas últimas décadas do século XX (anos oitenta e noventa). Para tanto, procurar-se-á dar ênfase ao estudo dos confrontos entre as diferentes posturas teóricas em relação à formação e à prática

${ }^{4}$ Lei de Diretrizes e Bases da Educação Nacional (Lei N. 9.394/96, de 20 de dezembro de 1996).

${ }^{5}$ FRANÇA, Eduardo D'Óliveira. Considerações sobre a função cultural da História. In: Revista de História, São Paulo, n. 08, 1951, p. 253-69; COSTA, Emília Viotti da. Os objetivos do ensino de História no curso secundário. In: Revista de História, São Paulo, n. 29, 1957, p. 117-20.

${ }^{6}$ FENELON, Déa Ribeiro..A formação do profissional de História e a realidade do ensino. In: Cadernos CEDES, Campinas, SP, CEDES/Cortez, n. 8, 1983, p. 24-31; NADAI, Elza. Análise da prática pedagógica e o ensino de História no 2 grau: problemas, deformações e perspectivas", In: Educação $\mathcal{B}$ Sociedade, Campinas, SP: CEDES/Cortez, n. 19, 1984, p. 134-46; CABRINI, Conceição. et al, O ensino de História: revisão urgente, 2. ed. São Paulo, Brasiliense, 1986. 7 SCHMIDT, Maria A.Op cit. p. 55. 
de ensino do professor de História nas recentes reformas curriculares vivenciadas pelo sistema educacional brasileiro, em especial, no Estado de São Paulo.

\section{Entre textos \& leituras}

A produção historiográfica que vem sendo apresentada no país nas últimas décadas tem apontado para a análise de temas clássicos sobre o ensino de História (produção do conhecimento, livro didático, ensino temático, apelo a diferentes linguagens, propostas de reforma curricular e a formação e a prática do professor de História) ${ }^{8}$ e para a defesa da permanente divulgação de experiências e debates nesse campo de estudo.

Dentro desta perspectiva, serão apresentadas algumas dimensões mais recorrentes sobre o "fazer" do professor de História no debate historiográfico, principalmente no que concerne à Reforma Curricular vivenciada pela disciplina no sistema educacional brasileiro nos anos oitenta e noventa.

A imagem do professor de História do ensino fundamental e médio nos últimos anos tem-se constituída pautada pela diversidade de opções teóricas presentes no discurso historiográfico.

Até os anos setenta eram muito poucos e inexpressivos os estudos referentes às questões do ensino de História produzidos no país, principalmente sobre o profissional desta área. A inexpressividade dos estudos relativos a esta temática é tão significativa quanto a direção em que trilhavam os poucos trabalhos existentes.

${ }^{8}$ FONSECA,Selva Guimarães. Ensino de História: diversificação de abordagens. In: Revista Brasileira de História, São Paulo: ANPUH/Marco Zero, v. 9, n. 19, set. 1989/fev. 1990, p. 197-208. 
Em linhas gerais, os escassos textos revelam, além de pouca preocupação com o ensino secundário, uma distinção entre os níveis de ensino a partir de uma postura diferenciadora entre o "fazer" do historiador e o do professor, sendo o primeiro "produtor" e, o segundo, "difusor" do conhecimento histórico. De acordo com Eduardo D'Oliveira França, "o historiador recolhe as experiências coletivas para que não se perca o trabalho do passado [...], o professor difunde as experiências sociais de um passado recente economizando esforço às novas gerações"

Esta distinção é nitidamente elaborada por Emília Viotti da Costa, em artigo publicado na Revista de História, em 1957. O referido artigo é apontado como clássico nas questões de ensino por sua argumentação acerca de uma divisão entre "História-Ciência" e "História-Matéria". Para Costa, uma e outra possuem caracteres e usos diferentes, sendo que para a História-Ciência "não precisamos buscar uma finalidade. Esta [...] justifica-se por si mesma", enquanto a História-Matéria é considerada um meio "de formar a personalidade integral do adolescente e, em segundo plano, fornecer-lhe conhecimentos básicos específicos"10.

Os textos de França e Costa, além de colocarem algumas perspectivas comumente atribuídas aos professores de História do secundário, como a uniformização operada pelo discurso científico, indicando a necessidade da padronização e da visão global para o ensino de História, sinalizam como determinados setores da comunidade acadêmica entendem o ensino e a função do professor secundário. No caso específico do texto de Costa, para Cláudia Sapag Ricci, ao elaborar os objetivos da História ensinada no secundário, fica visível uma concepção

\footnotetext{
9 FRANÇA, Eduardo D'Óliveira Op cit. p. 253/54.

${ }^{10}$ COSTA, Emília Viotti da.Op cit. p. 120.
} 
de História com "uma perspectiva instrumental, comportamental, moralizadora e formadora de mentalidades" 11 .

O discurso acadêmico, presente nestes textos, revela desde um desinteresse em relação à questão do ensino de História, evidenciado na quase inexistência de estudos sobre o tema, até uma visão depreciativa e desqualificadora sobre o professor de História de $1^{\circ}$ e $2^{\circ}$ graus, no que concerne a sua habilidade e possibilidade de elaboração, pela constante indicação de modos e tipos de aulas a serem ministradas, passando pela descrença na sua capacidade profissional.

Essas observações permitem identificar uma relação distante e hierarquizada entre a universidade e o ensino de $1^{\circ}$ e $2^{\circ}$ graus ${ }^{12}$.

Para a historiadora Maria do Carmo Martins, a Reforma Educacional de 1971, realizada pelos governos militares, transformou-se em um dos momentos emblemáticos da aproximação entre esses dois espaços. Enquanto os projetos educacionais dos militares não afetaram os saberes históricos acadêmicos, e estes podiam apenas tecer críticas à qualidade dos serviços educacionais, os historiadores pouco se preocuparam com os rumos do saber histórico escolar. Contudo, "no momento em que a definição dos saberes históricos escolares passou a interferir também no campo do trabalho acadêmico, percebemos a movimentação que resultou na 'luta contra os Estudos Sociais' e a aproximação dos historiadores com as

${ }^{11}$ RICCI, Cláudia Sapag. A Academia vai ao ensino de $1^{\circ} \mathrm{e} 2^{\circ}$ graus. In: Revista Brasileira de História, São Paulo:ANPUH/Marco Zero, vol. 9, n.19, set. 1989/ fev. 1990, p. 139.

${ }^{12}$ Essas observações são bastante ilustrativas por permitirem diversos paralelos com a forma como a História é constituída no $1^{\circ}$ e $2^{\circ}$ graus. Um momento significativo para a percepção de várias questões e concepções correntes no discurso e no exercício profissional dos professores de História de $1^{\circ} \mathrm{e} 2^{\circ}$ graus foi a discussão da nova Proposta Curricular para o ensino de História, em São Paulo, que ocupou diversos espaços. 
temáticas educativas e, conseqüentemente, com os professores de História do $1^{\circ}$ e $2^{\circ}$ graus" ${ }^{\prime 3}$.

A partir do final dos anos setenta e início dos oitenta, diante da mobilização das associações e entidades representativas, como a ANPUH (Associação Nacional dos Professores Universitários de História), contra o avanço dos Estudos Sociais dentro das escolas e universidades foi aberto maior espaço "para o ensino de História, para os relatos de experiências desenvolvidos no $1^{\circ}$ e $2^{\circ}$ graus e mesmo abordando a relação entre a formação e a prática" 14 dos professores de História.

Ao repensar a formação do professor de História, a historiadora Déa Ribeiro Fenelon, em artigo publicado nos Cadernos CEDES (1983), aborda, de forma pioneira, a possibilidade de produção/reprodução do saber relacionado à formação profissional de História e a realidade do ensino ${ }^{15}$.

Neste artigo, resultante de uma militância acadêmica e associativa da autora, que remonta à década de setenta ${ }^{16}$, Fenelon traz o debate sobre o ensino de História no $1^{\circ}$ e $2^{\circ}$ graus para dentro do universo acadêmico e das associações representativas com a preocupação de fazer avançar o diálogo entre universidade e escolas públicas, e também para estimular a reflexão sobre a formação do profissional de História dentro do contexto vivido pelo sistema educacional brasileiro.

${ }^{13}$ MARTINS, Maria do Carmo. A história prescrita e disciplinada nos currículos escolares: quem legitima esses saberes? Campinas, SP, FE - UNICAMP, Tese (Doutorado) 2000, f.. 186.

${ }^{14}$ RICCI, Cláudia Sapag. Da intenção ao gesto -quem é quem no ensino de História em São Paulo, São Paulo, PUC-SP, Dissertação (Mestrado) 1992, f. 58.

${ }^{15}$ FENELON,Déa Ribeiro Op cit. p. 24-31.

16 SILVA, Marcos Antônio; M. ANTONACCI, Maria Marieta Vivências da Contramão - produção de saber histórico e processo de trabalho na escola de $1^{\circ}$ e $2^{\circ}$ graus. In: Revista Brasileira de História, São Paulo: ANPUH/Marco Zero, vol. 9, n. 19, set. 1989/fev. 1990, p. 11. 
Fenelon tece críticas à postura acadêmica que defende a formação dos profissionais de História, ou sobretudo do professor, como "vulgarizador do conhecimento", posto que a mesma se processa dentro de um esquema tradicional onde se aceita "a dissociação entre a ciência e o social"17.

A referida autora rompe com esta postura ao defender a necessidade de se valorizar e incentivar a pesquisa, não apenas no curso de graduação, mas também em todos os níveis de ensino. Fenelon entende que essa tarefa (produção do conhecimento histórico) não pode ser "restrita à formação do pesquisador com suas sofisticações de tarefa maior que a do ensino". Para ela, não há distinção entre o "fazer" do historiador e do professor de História, uma vez que "o verdadeiro ensino sempre pressupõe pesquisa e descoberta" 18 .

Nessa perspectiva, o profissional de História desejado passa a ser aquele que "seja capaz de transmitir uma História viva e não morta, $[. .$.$] um profissional capaz de ensinar uma$ História na qual as pessoas possam se reconhecer e se identificar, porque [...] a História é uma experiência que deve ser também concretizada no cotidiano, porque é a partir dela que construímos o hoje e o futuro" 19 .

O autor Marcos Antônio da Silva, ao discutir as relações entre

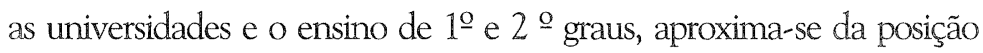
de Fenelon, ao rejeitar a postura que atribui "à universidade a produção de um saber erudito e desinteressado e à escola de $1^{\circ}$ e $2^{2}$ graus caberia divulgar [através do professor] para alunos passivos o conhecimento produzido naquele mundo da erudição" ${ }^{\text {"20 }}$.

\footnotetext{
${ }^{17}$ FENELON,Déa Ribeiro. Op cit. p. 26-7.

${ }^{18}$ Idem, p. 31.

${ }^{19}$ Idem, Ibidem.

${ }^{20}$ SILVA,Marcos Antônio A vida e o cemitério dos vivos. In: SILVA, Marcos A. (org.) Repensando a História, São Paulo: Marco Zero/ANPUH, 1984, p. 17.
} 
Este autor, ao desenvolver sua análise, questiona a historicidade da produção historiográfica, colocando a

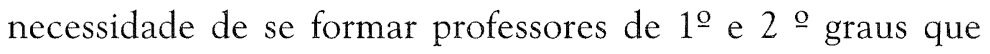
rompam com a fatalidade reprodutora e que enxerguem na possibilidade de produção do conhecimento histórico uma prática suscetível de transformação dos quadros de luta social ${ }^{21}$.

Durante a discussão dos novos currículos de História a partir de 1984, o historiador Pedro Paulo Funari retomará esta questão ao defender, assim como os autores citados, a necessidade de negar a visão com "que o aluno de graduação, enquanto futuro professor de $1^{\circ}$ e 2 o graus, é encarado, sempre como mero reprodutor de conhecimentos adquiridos - na melhor das hipóteses - ou, na pior como um total incompetente (palavra chave) e ignorante"22.

Essas discussões sobre o professor de História e a sua prática de ensino na sala de aula constituem tema de outro trabalho desenvolvido por um grupo de professoras da PUCSP, apresentando um relato de experiência de ensino de História numa escola de primeiro grau da periferia de São Paulo que fugia do modelo tradicional de ensino. As referidas professoras esboçam ao longo de seu estudo uma proposta de como desenvolver um ensino de História na quinta série, partindo de uma concepção que associa ensino e pesquisa, como havia proposto Fenelon, e de uma séria crítica à maneira como se dá a relação entre o 'saber' e o 'poder' entre os profissionais da área ${ }^{23}$.

\footnotetext{
${ }^{21}$ Idem, ibidem.

${ }^{2}$ FUNARI, Pedro Paulo A.Poder, posição, imposição no ensino de História Antiga: da passividade forçada à produção do conhecimento. In: Revista Brasileira de História, São Paulo: ANPUH/Marco Zero, vol. 8, n. 15, set. 1987/ago. 1988, p. 259-60.

${ }^{23}$ CABRINI, Conceição. et al, Op cit.
} 
O objetivo principal da proposta destas professoras é conseguir que os alunos realizem, com base em elementos levantados para o exame de uma determinada realidade histórica, algum trabalho de reflexão e análise que os leve à produção de conhecimento sobre esta realidade e à compreensão da forma como este conhecimento foi construído ${ }^{24}$.

A realização desta experiência pelas professoras serviu para evidenciar que se faz necessário "o caminhar junto dos três níveis de ensino, negando-se a separação entre produção e transmissão do conhecimento" e que "não se sai de um dia para o outro do velho para o novo e, apesar de todas as críticas que possam ser feitas [dificuldades teóricas, metodológicas e de didática], foi muito melhor a (s) professora(s) ter(em)-se lançado nessa experiência do que ter (em)-se mantido na melhor reprodução possível do ensino tradicional" ${ }^{\prime 25}$.

As dificuldades encontradas e enfrentadas por experiências de ensino como esta apontam para um outro problema extremamente grave dentro da questão da formação do profissional de História, identificado por Elza Nadai e retomado por outros professores nas discussões sobre a Reforma Curricular a partir de 1985, que se encontra estreitamente ligada à minimização da importância das discussões teóricas, metodológicas e historiográficas nos cursos de graduação. Para a autora, "o futuro professor recebe informações esparsas e incompletas, sobretudo das duas vertentes mais significativas da historiografia contemporânea - o materialismo histórico e a escola francesa dos Annales -, não conseguindo, entretanto, elementos para dominar os componentes fundamentais de cada uma destas escolas e nem elaborar uma visão de conjunto"26.

\footnotetext{
${ }^{24}$ Idem, p. 31-51.

${ }^{25}$ Idem, p. 115 e 127.

${ }^{26}$ NADAI, Elza.Op cit. p. 138-39.
} 
Além disso, Nadai destaca em seu artigo que, ao lado de estudos centrados nestas perspectivas, há a permanência e até o predomínio na universidade de uma visão positivista e até anacrônica da História.

$\mathrm{Na}$ leitura da referida autora, o resultado desta confusão não poderia ser diferente. $O$ aluno de graduação, quando formado professor de História, dificilmente terá condições de selecionar uma abordagem que garanta a apreensão da globalidade, apresentando o movimento real em seu conjunto. Portanto, este profissional, na dúvida do que fazer, acaba transmitindo "a mesma visão positivista herdada do século XIX e ainda muito real nos nossos dias, indicando uma permanência estrutural - a história historicizante ou episódica ("événementielle"). Elege-se [...] uma série de 'fatos históricos', isto é, fatos singulares, individuais que 'não se repetem', e não se opta por eles objetivamente. Organiza-se uma explicação coerente que constitui uma cadeia linear de causas e conseqüências, formando a síntese e a apresentação dos fatos estudados"27.

A perplexidade do professor recém-formado, retomando Fenelon, além da formação deficiente, vem também do distanciamento entre as propostas do ensino de História que ele mesmo adquiriu na universidade e a realidade da formação dos alunos com os quais terá de lidar ${ }^{28}$.

Todas essas discussões sobre o ensino de História ganham novo impulso a partir de 1984, com o retorno das disciplinas História e Geografia ao programa curricular das escolas de primeiro grau, quando ocorre um "boom" de novas propostas curriculares de História em todos os Estados brasileiros, na tentativa de concretizar a revisão crítica e a readequação dos

\footnotetext{
${ }^{27}$ Idem, p. 139.

${ }^{28}$ FENELON, Déa Ribeiro. Op cit. p. 29.
} 
programas curriculares e metodologias de ensino, com a finalidade de redirecionar as disciplinas ao ensino fundamental de oito anos ${ }^{29}$. A História tradicional, nesta conjuntura, passa a ser questionada com maior ênfase ${ }^{30}$. Novos recursos teóricos e metodológicos que fugiam de uma História descritiva e acrítica e que estimulava um ensino analítico, crítico e mais interessante para os professores e alunos são sugeridos, abrindo espaço para o estudo de temáticas ligadas a uma História social, cultural e do cotidiano ${ }^{31}$ através da prática de debates e pesquisas na sala de aula.

Esses debates sobre a Reforma Curricular do ensino de História começam a identificar outros problemas referentes não apenas à formação do professor, mas também sobre sua prática. Experiências vivenciadas por profissionais envolvidos com o debate sobre o ensino de História, no caso específico do Estado de São Paulo, afirmam que, quando apresentada e discutida a proposta curricular de História da CENP (Coordenadoria de Estudos e Normas Pedagógicas) com os professores da rede estadual de ensino constatou-se que esta parecia ter marginalizado o professor, esquecendo de levar em consideração seu cotidiano apesar de valorizar o dia-a-dia dos alunos ${ }^{32}$.

Ao analisar a questão do papel desempenhado pelos professores dentro da elaboração e aplicação dos novos currículos de História, Paulo Celso Miceli traz para o debate sobre a Reforma Curricular a necessidade de se dar atenção

${ }^{29}$ F. BITTENCOURT, Circe Maria F.(Org) Capitalismo e cidadania nas atuais propostas curriculares de História. Op cit., p. 11-27.

${ }^{30}$ NADAI, Elza. O ensino de História no Brasil: trajetória e perspectivas, In: Revista Brasileira de História, São Paulo: ANPUH/Marco Zero, vol. 13, n. $25 /$ 26, set. 1992/ago. 1993, p. 142-162.

${ }^{31}$ FONSECA, Selva Guimarães. Caminhos da história ensinada, Campinas, São Paulo: Papirus, 1993, p. 85-6.

${ }^{32}$ MICELI, Paulo Celso. História, histórias: o jogo dos jogos. Campinas, São Paulo: UNICAMP - IFCH, 1996, p. 284-86. 
ao cotidiano destes profissionais. Para este autor, os professores, por falta de tempo ou condições, têm sido cada dia menos estimulados e qualificados, o desânimo e o receio de ensinar é enorme, ficando assim a educação em posições trocadas e em caminhos opostos no país ${ }^{33}$.

O modelo de professor de História idealizado no interior das propostas curriculares, na leitura deste autor, não corresponde ao professor real que tem seu ofício diariamente transformado na "vergonha do subemprego, denunciado nas imensas filas dos 'bancos oficiais' nos dias de pagamento e na reduzida presença dos professores em filas outras que prometem o lazer, o prazer ou o acesso a formas de cultura que acabaram elitizadas, como o teatro e, até, o cinema" ${ }^{\text {"34. }}$

Em todos os debates nos quais se colocam questóes relativas ao ensino e/ou pesquisa histórica, de acordo com as professoras Joana Neves e Zeluiza Brandão, "emerge/surge a questão das condições efetivas e concretas do professor (ou em casos específicos, do eventual pesquisador). De modo geral, essa questão apresenta-se da seguinte forma, as condições de trabalho são tais que inviabilizam um ensino adequado" 35 .

Por isso, na maioria das vezes, observa-se nestes debates a configuração de um confronto entre dois modelos de profissionais no ensino de História: o professor ideal (apresentado nas propostas curriculares de História) e o professor real (marcado por uma formação deficiente, em sua maioria, e condições precárias de trabalho) ${ }^{36}$.

\footnotetext{
${ }^{33}$ Idem, p. 287.

${ }^{34}$ Idem, p. 300.

${ }^{35}$ NEVES Joana ; Zeluiza BRANDÃO. Condições de trabalho do professor de História. In: Revista Brasileira de História, São Paulo, ANPUH/Marco Zero, vol. 6, mar./ago, 1986, p.216.

${ }^{36}$ VILLALTA, Luiz Carlos. Dilemas da relação teórica e prática na formação do professor de História: alternativas em perspectiva. In: Revista Brasileira de História, São Paulo: ANPUH/Marco Zero, vol. 13, n. 25/26, set. 1992/ago. 1993, p. 223-232.
} 
Para Luiz Carlos Villalta, o professor ideal tem se tornado cada vez mais uma 'miragem' em um imenso 'deserto' em que se enquadra o ensino brasileiro ${ }^{37}$. A longa distância entre o professor ideal e o real percebe-se, de maneira tímida, quando se estuda as falas dos professores de História entrevistados e questionados sobre a qualidade de sua formação e as sua reais condições de trabalho ${ }^{38}$.

Este distanciamento presente entre os dois modelos de professor de História pôde ser identificado pelas professoras Dulce Camargo, Ernesta Zamboni e Maria Carolina Galzerani em entrevistas com professores de História do Distrito de Barão Geraldo, em Campinas/SP, quando, apesar de perceber nas falas dos professores, "implicitamente um descrédito das concepções fechadas e absolutas de História", verificou-se "também um certo desânimo que pode implicar numa imobilização"39.

Já para Cláudia Ricci, o distanciamento entre esses dois modelos encontra-se na ausência de um ponto de encontro entre os discursos dos professores de História e a Reforma Curricular que vem sendo realizada desde os anos oitenta, no caso paulista.

Esta autora, em sua pesquisa, analisa as percepções dos professores da rede estadual de ensino de São Paulo, a respeito do seu trabalho, seu papel, sua formação, suas concepções sobre a História e a produção do conhecimento histórico, no período de discussão da Reforma Curricular entre 1985 e 1987. Demonstra a profunda heterogeneidade de concepções entre o professorado paulista de História, revelando um tempo de

\footnotetext{
${ }^{37}$ Idem, p. 223.
}

${ }^{38}$ CAMARGO, Dulce Maria P.de. et al. Sabores e dissabores do ensino de História. In: Revista Brasileira de História, São Paulo: ANPUH/Marco Zero, vol. 9, n. 19, set. 1989/fev. 1990, p. 181-95.

${ }^{39}$ Idem, p. 189. 
execução das políticas do Estado (no caso da Reforma Educacional do pós Ditadura Militar) que não coincide com o tempo necessário para construção de um projeto comum dos educadores $^{40}$.

Em sua análise deste contexto de Reforma Curricular no Estado, Ricci conclui que o que transpassa toda essa diversidade de concepções, "seja ela da academia ou do $1^{\circ}$ e $2^{\circ}$ graus, é a perda paulatina do significado do papel social do professor (de História)" $" 11$.

A historiadora Vera Lúcia S. De Rossi, ao pesquisar sobre o trabalho realizado nas delegacias de ensino, por professores / monitores de História em sua atuação no Projeto Pedagógico "Reorganização do ensino de $1^{\circ}$ grau", que envolveu profissionais de educação de todas as escolas públicas estaduais de Campinas e região de 1984 a 1988, aproxima-se da análise de Ricci, ao focalizar uma luta específica no campo pedagógico ligada às outras lutas materiais da classe trabalhadora, como um dos fios do processo histórico mais amplo, ou seja, através das relações de professores/monitores de História com as equipes pedagógicas do Projeto pedagógico e com os representantes do Estado na CENP/SE, no decorrer da Reforma Curricular que coincide com o momento político de (re)democratização do Estado de São Paulo ${ }^{42}$.

Os professores de História da região de Campinas, segundo a autora, ao analisarem a proposta curricular para a disciplina, apresentaram posturas divergentes. Além de

\footnotetext{
${ }^{40}$ RICCI, Claudia Sapag. Op cit.1992, p. 13-14.

${ }^{41}$ Idem, p. 135.

${ }^{42}$ DE ROSSI,Vera Lúcia Sabongi. Refazendo a escola pública? Tropeços e Conquistas: investigação documental acerca do trabalho de professores/ monitores de História no Projeto Pedagógico de Campinas e região - 1984/ 1988, Campinas, SP, Dissertação (Mestrado),UNICAMP,São Paulo, 1994.
} 
questionarem a bibliografia adotada na proposta, as falas dos professores "apontam a necessidade de 'mecanismos reais de participação' no processo de elaboração, pois não aceitam a idéia 'do professor cumpridor de tarefas de um grupo restrito', com 'elocubrações teóricas', 'privilegiando o conhecimento do $3^{\circ}$ grau', ou se 'alimentando do saber acadêmico'”43.

Em suma, para De Rossi, os professores de História consideraram que algumas das principais contradições da referida proposta eram oriundas do fato de "desconsiderarem as experiências do $1^{\circ}$ e $2^{\circ}$ graus, suas barreiras, contradições e dificuldades, chegando alguns grupos a sugerirem que a construção de propostas se dê na própria escola" ${ }^{44}$.

Ao defenderem a proposta de construção do currículo no espaço da própria escola, estes grupos apresentam uma imagem idealizada do professor de História real, uma vez que, de certa forma, desconsideram o despreparo deste profissional, tanto na sua formação, quanto na sua prática cotidiana, para elaborar uma proposta de ensino que rompa com a História tradicional.

A diversidade de posturas em relação à Reforma Curricular em São Paulo foi evidenciada por Maria do Carmo Martins no interior da própria CENP ${ }^{45}$.

Em sua pesquisa, Martins trata da construção da proposta curricular de História, entre os anos de 1986 e 1992, e da relação que a CENP estabeleceu com o processo de confecção da referida proposta, que esteve envolvida em vários conflitos e polêmicas relacionadas a diferentes concepções de escola, currículo, História e professor entre os seus autores e a

\footnotetext{
${ }^{43}$ Idem, p. 56.

${ }^{4}$ Idem, p. 57.

${ }^{45}$ MARTINS,Maria do Carmo. A construção da proposta curricular de História da CENP no período de 1986 a 1992: confrontos e conflitos, Campinas, SP, Dissertação ( Mestrado), UNICAMP, 1996.
} 
coordenação da instituição. Algumas desses conflitos foram frutos de discussões acadêmicas e políticas tornadas públicas pela imprensa ${ }^{46}$.

O confronto entre o ensino de História ideal e as reais condições do ensino e de trabalho do professor, no caso das discussão em torno da Reforma Curricular em São Paulo nos anos 1980 e 1990, na análise de André Luiz Joanilho, estaria nitidamente vinculada a uma certa 'ingenuidade' presente nas propostas curriculares, uma vez que estas acreditam "que o tema definirá o modo de trabalhá-la, ou seja, os fins implicam automaticamente os meios" $"$.

De acordo com este autor, os novos currículos paulistas esqueceram de levar em consideração aspectos significativos da formação do professor de História e suas condições de ensino na sua elaboração, especialmente no que concerne à prática da pesquisa em sala de aula. Pois, "é sabido que um grande número de professores não praticou a pesquisa em seus cursos de graduação, e sem esta prática, efetivamente, não é possível executar a contento as sugestões da CENP, não por incapacidade dos profissionais, mas por falta absoluta de contato com a pesquisa histórica ${ }^{48}$.

Joanilho retoma pontos sobre a formação dos professores de História que já vinham sendo postos em debate 'dentro' e 'fora' da academia no final dos anos setenta, mas que foram deixados de lado quando feita a reforma educacional. A inviabilidade de uma proposta como a da CENP, em São Paulo, explica-se para este autor pelo despreparo dos profissionais que têm de aplicá-la na sala de aula ${ }^{49}$.

\footnotetext{
${ }^{46}$ Idem, p. 52-78.

47 JOANILHO, André Luiz. História 8 Prática: pesquisa em sala de aula. Campinas, São Paulo: Mercado das Letras, 1996, p. 11.

48 Idem, ibidem.

${ }^{49}$ Idem, p. 48-59.
} 
Ao analisar os novos currículos produzidos nos anos noventa no Brasil, a historiadora Circe Maria F. Bittencourt concorda com as afirmações de Joanilho ao constatar que estas propostas são falhas porque trabalham com uma concepção diferente de professor: intelectual-pesquisador ${ }^{50}$.

Entretanto, segundo esta autora, a falha destas propostas não está na concepção de um professor diferente e, sim, na falta de uma menção "à forma como essa mudança essencial e necessária do trabalho docente, será concretizada para efetivação das propostas curriculares [inclusive os próprios Parâmetros Curriculares Nacionais] "51.

Observando de diversos ângulos os debates sobre a Reforma Curricular paulista, pode-se evidenciar que as discussões têm girado, direta ou indiretamente, em torno do conflito entre diferentes discursos sobre o papel do professor de História no ensino fundamental e médio.

As recentes reformulações ocasionadas pela nova LDB de 1996 são identificadas como significativas para a ampliação dos debates sobre a questão da reforma do sistema educacional nacional. No caso específico da disciplina História, os debates estão concentrados nas propostas apresentadas pelos Parâmetros Curriculares Nacionais para o ensino fundamental e nas determinações da referida Lei para os cursos de graduação, principalmente no que concerne à formação de professores.

Para a historiadora Kátia Maria Abud, a elaboração, nas instituições do poder central (MEC), dos Parâmetros

${ }^{50}$ BITTENCOURT, Circe Maria F. Propostas Curriculares de História: continuidades e transformações, In: BARRETTO, Elba S. de Sá. (Org.), Os currículos do ensino fundamental para as escolas brasileiras, Campinas, São Paulo: Autores Associados/São Paulo, Fundação Carlos Chagas, 1998, p. 157-58.

${ }^{51}$ Idem, ibidem. 
Curriculares Nacionais e conteúdos mínimos para todo o país representa um entrave nos debates sobre a renovação do ensino de História, uma vez que significa a "retomada da centralização da educação que alija da discussão os seus principais sujeitos: alunos e professores novamente vistos, como objetos incapacitados de construir sua história e de fazer, em cada momento de sua vida escolar, seu próprio saber" ${ }^{252}$.

Em linhas gerais, de acordo com Maria A. Schimidt, o que se tem constatado nas pautas e discussões de obras, periódicos, encontros e congressos nos últimos anos, é que não há um diálogo aberto e claro entre a elaboração das propostas curriculares, a formação do professor de História e a sua prática cotidiana na sala de aula.

Afastando-se das análises fechadas (professor real versus professor ideal) sobre a imagem do professor de História a partir das discussões historiográficas concentradas na perspectiva dos novos currículos, a autora aponta para a necessidade de se "falar do significado da formação do professor e do cotidiano da sala de aula, do seu dilaceramento, embate e fazer histórico" 53 .

Enfim, falta vida nessas histórias. E me questiono: onde estão os professores?

${ }^{52}$ Kátia Maria ABUD, Currículos de história e políticas públicas: os programas de História do Brasil na escola secundária In: BITTENCOURT, Circe Maria F. (org.), Op cit. p. 40.

${ }^{53}$ Maria A. SCHMIDT,Maria A.Op cit., p. 56. 


\section{Palavra aos "combatentes" pela história}

"Amo a história. Se não a amasse não seria historiador. Fazer a vida em duas: consagrar uma à profissão, cumprida sem amor; reservar a outra à satisfação das necessidades profundas - algo de abominável quando a profissão que se escolheu é uma profissão de inteligência. Amo a história - e é por isso que estou feliz por vos falar, hoje, daquilo que amo"

Lucien Febvre - Combates pela História (Lisboa, 1986)

Gostaria de encerrar este ensaio fazendo uma proposta e uma homenagem. Primeiro, a proposta: Vamos nos aventurar pelos labirintos do conhecimento e das histórias de vida dos professores (de História); vamos experimentar a doce prática de ouvir estas histórias. Talvez o segredo de se descobrir o universo destes profissionais esteja na coragem e vontade de embarcar nessa viagem (aula de História) "longa e difícil, para os aprendizes como para o guia, através do tempo e do espaço", como diria Fernand Braudel.

Nesta aventura pelos labirintos da construção do saber histórico e pelos jardins da memória dos nossos professores poderemos encontrar diversas faces e olhares, sentimento, experiências e diferentes maneiras de se contar histórias. Enfim, maneiras de ser, saber e interpretar o mundo ... e a História. Isto, nenhum currículo será capaz de nós oferecer: a vida em toda a sua plenitude (com suas alegrias, tristezas, sonhos e desilusões).

Meus caros leitores, se existe um professor ideal ou real, creio que este tenha muitas faces e muitas histórias para contar. Histórias que poderiam muito bem começar assim: Era uma vez ...

Por último, a homenagem: eu tive o prazer de conhecer durante os anos de graduação uma figura muito especial - um professor apaixonado pelo que fazia. Sua oficina era cheia de vida. Ele vivia a história como propunha Lucien Febvre: com 
amor. Seu rosto, seu olhar sempre deixava uma marca indelével por onde passava, sempre carregando entre os braços livros e fichas (o que ele chamava de forma bem humorada de "peso do saber"). Um dia ele resolveu ir garimpar em outros terras, tão distantes... e deixou aqui a saudade e o exemplo de "que tudo vale a pena se a alma não é pequena", como diria o poeta Fernando Pessoa. Lições diárias de dedicação e amor pelo ofício de professor. Um homem com o coração dividido entre a História e a sua Cidade (Campinas), dois amores que o acompanharam durante toda a sua vida. Obrigado professor José Roberto do Amaral Lapa, ou "Lapa" (in memoriam); uma das muitas faces da nossa história, da história do ensino de História. Saudades.

\section{Agradecimentos}

Este artigo corresponde uma versão modificada e ampliada da comunicação livre apresentada na mesa "Construções e apropriações do discurso historiográfico" no IV Encontro de Estudantes de História da Universidade Estadual de Campinas, realizado entre 08 e 11 de setembro de 2001 no auditório do Instituto de Filosofia e Ciências Humanas desta instituição. Os resultados de pesquisa apresentados neste texto só foram possíveis graças ao financiamento do PIBIC UNICAMP/PRP - CNPq (agosto de 2001 a julho de 2002). Gostaria de agradecer, nesta oportunidade, ao Prof. Dr. Paulo C. Miceli, pela orientação desde maio de 1998, quando lendo um texto de Fernand Braudel, para o curso de "Introdução ao Estudo da História", iniciei minha viagem pelos caminhos da história ensinada. Quero deixar registrado aqui o meu carinho e admiração pelos professores Pedro Paulo A. Funari e Celia Maria Marinho de Azevedo pelo tanto que me ensinaram nesses 
anos de formação. Especial agradecimento aos colegas da República dos "Untouchables" (M12-A) (Alexandre Abdalla, Helder Rodrigues, Léo Barra, Danilo de Martins e Mairon Valério), pelo apoio e paciência com este amigo nestes anos de formação. Contudo, devo ressaltar que as idéias aqui presentes são de inteira responsabilidade do autor.

ABSTRACT:

The present article analyses the major historiographic debates about the History teachers role in Brazil during the previous decades (1980's and 1990's). The History professional (teachers) studies have been related with the discussion about the changes of the teaching of this discipline since the ending of 1970's and beginning of 1980's in Brazil.

KEY-WORDS:

Teaching, Teachers; Historiography 